\title{
User's demography and expectation regarding search, purchase and evaluation in mobile application store
}

\author{
Wilson Prata ${ }^{\mathrm{a},{ }^{*}}$, Anamaria de Moraes ${ }^{\mathrm{a}}$ and Manuela Quaresma ${ }^{\mathrm{a}}$ \\ ${ }^{a}$ LEUI, Pontificia Universidade Católica do Rio de Janeiro (PUC-RIO), Rua Marquês de São Vicente, 225, \\ Gávea, Rio de Janeiro, RJ - Brasil - 22451-900
}

\begin{abstract}
This article is result from a questionnaire about mobile app store usage. The objective of this work was to collect information about user needs and opinion regarding search, purchase and evaluation process in Android Market, Apple App Store, BlackBerry App World and Nokia Ovi Store. The data collected was analyzed to identify the positive and negative usability aspects, if the process to perform these task are any different in those stores and if the users are satisfy with their store or if they have any complains about it. Its covers the brazilian market only.
\end{abstract}

Keywords: Human-Computer Interaction; Usability; Research methods, Questionnaire

\section{Introduction}

Nowadays mobile phones are the most used tools for wireless communication. Mobile communication works through electromagnetic waves, using this kind of technology, mobile device can perform twoway transmission of voice and data in a coverage area divided by cells. These waves can vary of technology and potency, from $1 \mathrm{G}$ networks (analog, developed in the early 1980s) to third generation networks, 4G (digital, under development). With the emergence of $2 \mathrm{G}$ networks it has been possible the transmission of data packages, this possibility incentives the manufactures to develop a new kind of mobile phone, a smartphone, an devices that could take advantage of this new network capability. The difference of a smartphone from other mobile phones is that it has an open operational system which enables the installation of third parties programs as widgets and applications what could be done over the air [9].

Mobile communication devices are present in everyday life of most Brazilian people and also the smarphones. In the first quarter of 2011 Brazil's presents a mobile phone penetration rate of $80 \%$ per- cent, from those devices only $5.8 \%$ were smartphones but its represents a grow of $165 \%$ compared with 2010 [7] the predictions for 2011 is that more than 10 millions smartphones will be sold in Brazil [3].

Although smartphones are more expensive than traditional mobile phones, their fast growth can be justified by the interest of users in it capabilities to access internet, download and execute entertainment media content as music and games [14]. The rapid growth of both mobile technologies and device capabilities has fueled the expansion of the mobile internet, it is one of the key factors of the success of mobile commerce [17]. To meet the demand for this kind of content many manufacturers and software houses developed their own stores which enables third party content distribution, it's usually called app store or application store. Its distribution model arises and gain popularity due to the difficulty and complexity of the old channels as content aggregator, developers website, telco portals. Nowadays over $45 \%$ of the mobile app developers use an app store as their primary route to the market [3] "(...) with the introduction of Apple's iPhone we have seen a revo-

\footnotetext{
*Corresponding author. E-mail: wilsonprata@gmail.com
} 
lution in creating, distributing and selling mobile applications and services, and several other manufacturers have followed suit by introducing similar mechanisms, including the Android Market and Nokia's Ovi Store" [10].

\section{Problem, objective and justify}

\subsection{Problem}

The capability to installing additional applications on their devices, besides the pre-installed ones, is what instigate many users to purchase an smartphone, since it can maximize the usage of their mobile phones beyond voice communication. With a receptive market for applications several manufacturers, followed by Apple example, have or are developing an application store [6]. It also possible to observe the arising of many independent stores, non-related with one manufacturer only, as mobile carriers stores [16].

Despite this impressive growth, there has been several usability problems in the application stores. Some of these problems could be related with the finds of a study conducted by the Customer Experience Management that estimate that $75 \%$ of online shopping are abandoned before users make the checkout [4]. It's also possible to notice that most of the issues and complains presented in physical stores, are also presented in virtual stores, such as search issues, selection and checkout of the items [15].

\subsection{Objective}

This work covers the four main application stores available in Brazil: Android Market, Apple App Store, Blackberry App World and Ovi Store. Its objective is to collect information about users needs and opinion regarding search, purchase and evaluation tasks in these app stores and identify which usability problems presented in those stores are related with the abandon of the purchases. To better evaluation of these topics, it's also important to check if the users are are aware of mobile application store content distribution model and if they use it and if they are satisfied with the overall experience in use it, since it is almost mandatory the usage of its channel to get access to most of the applications available to their devices.

\subsection{Justify}

The first point is the relevance of the mobile App to the end user. Apps are responsible for $56 \%$ of all smartphone daily activity [11] what confirm that app usage is one of the main reason from a user to move from an ordinary phone to a smartphone. Other point is the quantity of decisions that a user need to do in the App Store environment, if we observe that only Apple has more than 200,000 items in its store [6] it's important to check if the users can achieve their objectives when dealing with this huge amount of options. The same question can be done to the others stores as well, yet some of them don't have this amount of content the tendency to the next years are of continuing grow [6].

The enormous interest of manufactures and other players that are developing a/for an App Store are justified by the fact that only in 2010 they had revenues of $\$ 2.2$ billion in the first six months, with approximately 3.9 billion downloaded applications [12] and the forecast is of continue growing of both phone and network capability. The prediction of the user's interest in new Apps and the number of Apps available in the market follow the tendency of growing of this market [6].

Although many researches had been done about users behaviors and opinions related to Apps Stores $[6,10,12,15]$ few of them had covers the Brazilian market [13], and even the one available do not covers all the points that this research aim to approach.

\section{Methodology}

\subsection{Research technique}

To achieve the objective of any Human-Computer Interaction research the first thing to be done is to define the user profile [5]. It's possible to do by in field research or by the analysis of pre-collected data, this research aim to identify the profile of mobile application stores' users in Brazil. Altough there is some information available about this user profile its important to perform a field research since not all the research's questions are covered by current data. This research aim to gather demographic data, overall opinion and satisfaction related to the App Store. It's also important to check if these results vary from vendor to vendor.

The main point here is to choose one technique that will provide the most relevant information to the questions that the research wants to clarify. In order 
to gather this information an online questionnaire was developed. Surveys and questionnaires are the most frequently used research techniques because it provides precise estimates of the prevalence of some variable of interest. It's a research techniques that consist in asking for a specified group of people a certain amount of questions, its application can be online or offline $[1,5]$ its aim to measure and/or collect a population opinion about a specific topic $[1,2$, $5]$.

\subsection{Questionnaire development}

To develop a questionnaire the first thing is to define the questions that we want to clarify, these are not the questions that will be present to the participants, those will be unfold in less intrusive or indirected questions, some will be presented as open questions other as multiple choice or as an evaluation scale. Based on these research questions a draft questionnaire was developed, it used the tunnel approach to filter the participants based on the habits of use of mobile application stores. The funnel approach "starts off the module with a very broad question and then progressively narrows down the scope of the questions until in the end comes to some very specific points" [1].

The questionnaire was divided in four main steps. The first one, is a welcome screen in which it explained the terms and objectives of the research in a introduction text, additionally it invites the user to start to fill the survey there is only one question in which the participant selects the manufacturer of his/her smartphone. Then the participant is conducted to the second step, with questions related with smartphone usage and awareness of the app store, there is a filter that will conduct the participants or to the third step with questions related with app store usage, and then the fourth and last step with demographic questions, or, in case that the participant is not aware or do not use the app store, redirect them from the second to the fourth step.

\subsection{Pilot test}

As suggest by some authors $[1,5]$ the questionnaire was revised a couple of times by the researchers to check if it fits all the research needs. Then a pilot test with nine participants was conduct, although in it final version the participants will fill the questionnaire by themselves, without a researcher intervention/support, the pilots were conduct in a face-to-face session so it was possible to check participants' facial expressions and overall behavior while they fill the questionnaire. The think aloud technique was used as well, what helped to identify the pain points in the questionnaire. These tests were conduct with the questionnaire in it final form (online at wufoo.com), an introduction text explained the terms to selection, confidentiality, anonymity, length. The usage of online questionnaire provided a good appearance and it's important that wufoo uses traditional web elements in its fields (box like buttons to checkbox, radial buttons to single choice questions, etc.) what reduce the amount of instructions of how to reply the questions. After the pilot tests, the questionnaire was revised to include user suggestions and some questions were eliminated and other reformulated.

\subsection{Applying the questionnaire}

The invitation to gather users to fill the questionnaire were done essentially online. It was used mail and social network invitations; we choose the tree main social network services in Brazil (Orkut, Facebook and Twitter) and internet forums related to technology, with topics as computers and games. Facebook groups and Orkut communities related to technology, smartphones and games were other channels where the questionnaire was promoted.

Some suggested techniques to increase response rates were used. The invitation has a important role as a first contact with the participant, in this contact it was explained the purpose of the research, the institution that were involved and supporting the research and the average time that the used were spent to fill the questionnaire (it was obtained by the average time of the respondents that participated in the pilot test). Wuffo provided the feature of address customization of the questionnaire, it was decided to use the same name in the invitation title, questionnaire title and the link name not only because it reinforce the message but also because the research was focusing on a specific part of the population. Keep clear the research proposal and benefits help users that don't fit the profile to avoid a task that is not relevant to them and could encourages the participants that fit in the profile to fill in the questionnaire, moreover it clarify that the invitation is not a spam. 


\section{Results}

The questionnaire was promoted on online, on social network websites (like Facebook and twitter) and by mail chain. The results covers the Brazilian market only, a total of 321 responses were gathered (237 male, 84 female) during the span of seven weeks in the second quarter of 2011. Most of the participants were in the age range of 21 to 30 years $(56.4 \%)$ followed by the users in the range of 31 to 40 years $(27.7 \%)$.
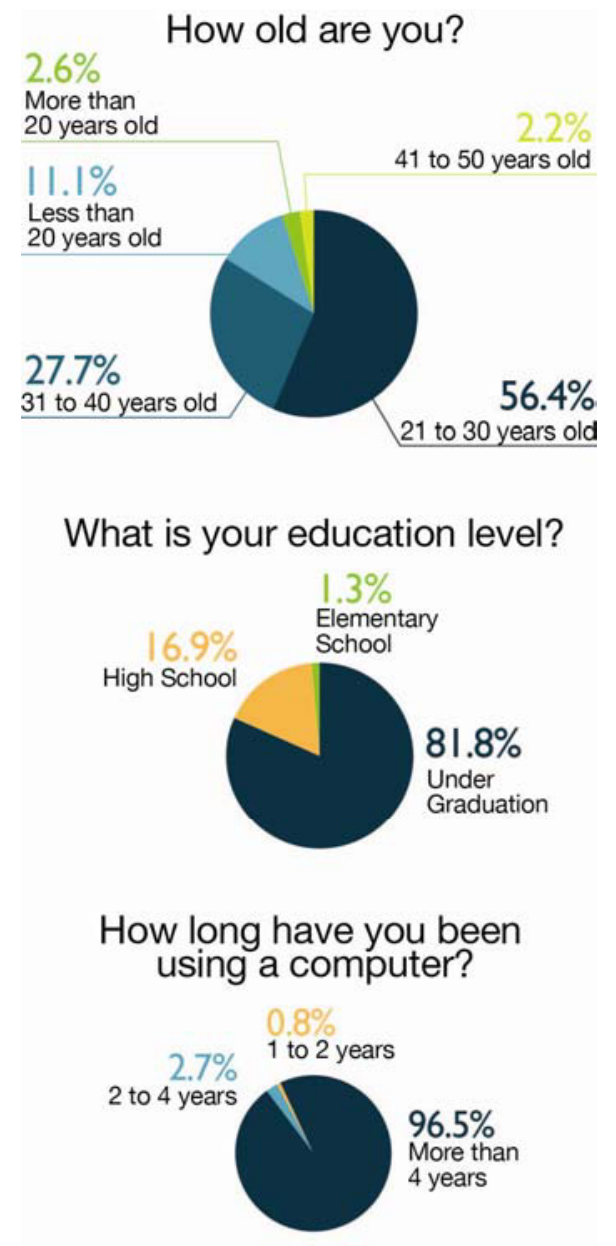

\section{How long have you been using a smartphone?}

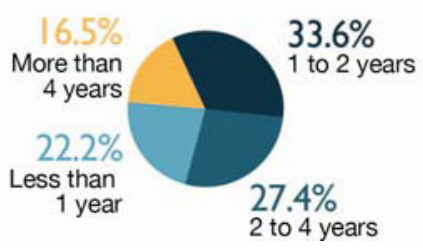

About the usage of the application store, it's relevant to observe that $6.3 \%$ of the respondents said that they don't know the dedicated application store for their smartphone. From those who use their application store, $67.5 \%$ had reported frequent problems when searching for applications, in all stores, the most usual way to search for an application is browsing the categories.

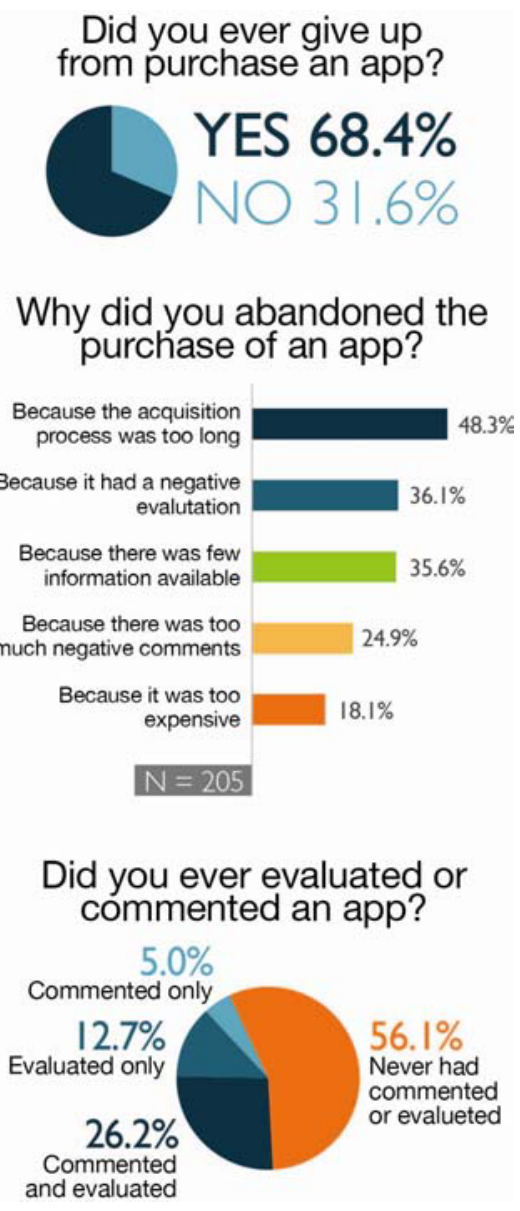

A high number of users (68.4\%) had already given up an application acquisition in the middle of the purchase, the reasons are the same from store to store but they have different score among the those. A representative number of the respondents usually provide their feedback and opinion about the apps that they had purchased, $43.9 \%$ had said that they had at least once commented or ranked an application. A high number of participants $(90.3 \%)$ have declared that they had at some point a problem or disappointing experience in the usage of the store or with an app but a good number of users (74\%) described themselves as satisfy or high satisfy with the store. 
Do you know the official app store available for your smartphone?

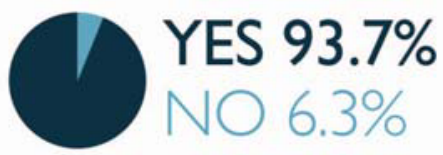

Did you ever downloaded an app that had disapointed you?

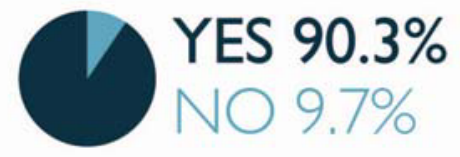

How do you choose your smartphone apps?

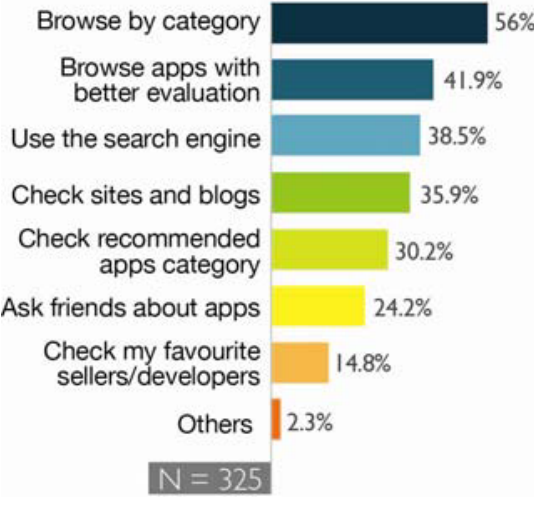

How is your satisfaction level with the applications avaliable for yor smartphone?

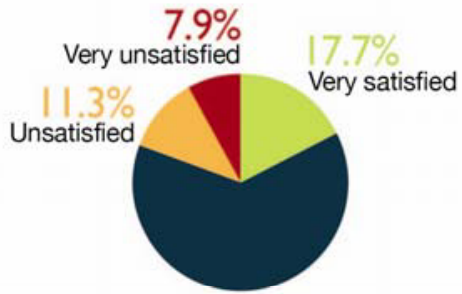

$63.1 \%$

Satisfied

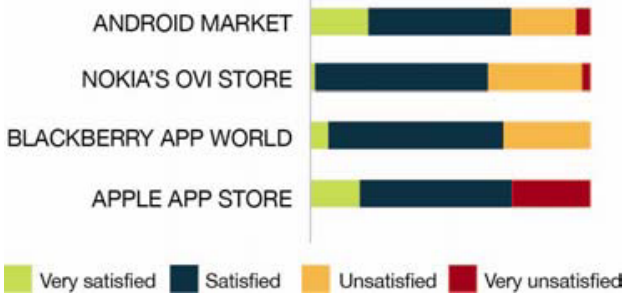

It was possible to identify that most of the users of smartphones that respond the research have a high level of technology familiarity since $96.4 \%$ have been using computers for more than 4 years and $77.8 \%$ have been using smartphones for more than 1 year. It's important to highlight that the questionnaire was applied online so we can assume that $100 \%$ of the users that replied it have access to internet or in the smartphone or in a computer. The participants shown a high education degree, 266 participants $(81.8 \%)$ had concluded or are doing a under graduation degree and from those 84 participants have a graduation degree.

\subsection{Android Market}

From 147 responses of Android users, 82.3\% consists of male against $17.7 \%$ of female users. Most of them are in the age range of 21 to 30 years $(57 \%)$ but there were a good number of respondents between 31 to 40 years $(23.5 \%)$ and the store is the one with more users with more than 40 years $(5.4 \%)$. Almost the totality of these users have been using computers for more than 4 years $(96.6 \%)$ and $69.8 \%$ of them had having a smartphone for more than 1 year. The majority of users had a under graduation degree $(83.2 \%)$ and from those, $38.1 \%$ of them have a graduation degree.

The android users are the ones that provided the highest number of responses describing themselves as frequent users of their app store. The most common reason why android users gave up of the acquisition of an app is when it has too many negative comments $(23.76 \%)$, or because it was too expansive $(18.78 \%)$ or because of the lack of information about the app (17.68\%). Android users are satisfied or very satisfied with their store $(74.5 \%)$ but $91.5 \%$ of them have at some point a disappointment with an app. They usually share their opinions about apps, 51.77\% of them had ever commented or ranked an app at least once.

To Android users the search engine is one of the main good features of the store, consequently those user also reported how easy is to find and install an app. Android users appreciate the number of free apps available in the store and reported it as a important aspect of the store. The integration between mobile and desktop was another popular feature and it is one of the items that are related with an much appreciated store's usability. The variety of apps, store's look and feel and the integration with the google account were other important aspects. 
Although the high number of free apps is a positive aspect, one of the main complains is related with the high number of useless apps or apps without proper description or in a language other than the one of user. There is a perception that there is no criteria to publish an app in the store or if there is, it is too weak. The high use of the search engine could be associated with a problematic categorization, according with user perceptions. Other criticized aspect of the store is the absence of filters to be used with the search engine.

\subsection{Apple App Store}

From 95 responses of iPhone users, $65.4 \%$ consists of male against $34.6 \%$ of female users. Most of them are in the age range of 21 to 30 years $(56.1 \%)$ but there were a good number of respondents between 31 to 40 years $(30.5 \%)$. Almost all of the respondents $(99.8 \%)$ informed that they've been using computers for more than 4 years and only $13.4 \%$ have been using smartphones for less than 1 year, $34.1 \%$ of all respondents have been using smartphone for more than two years and $20.4 \%$ for more than four years, the highest number among all stores. A high number of respondents have been using their current smartphone model for less than six months, what is correlated with the recently lunch of iPhone 4 which correspond to $61.5 \%$ of responses. The majority of users had a under graduation degree $(85.3 \%)$ and from those, $53.6 \%$ of them have a graduation degree.

The iPhone users are the most satisfied with the store $(82.2 \%)$ but the number of users that are not satisfied with the store is rather representative, a interesting aspect of these users is that they described themselves as "high unsatisfied" (17.7\%) with no responses as "unsatisfied", only. They are the most aware of the availability and existence of the app store only $1.1 \%$ of the them said that don't know or don't use the store. Even with the high number of app available in the store $55.7 \%$ of the users informed that they are satisfied with the number of apps available on the store.

These users are usually open to suggestions, they are confident in the store feedback tools and the opinion of other users. It's common to these users to choose the apps with better evaluation $(48.42 \%)$ and browse in Top Charts (43.16\%) when they are looking for an app. Other statistic that support this behavior is the number of users that have commented and/or ranked an app, $45.57 \%$ of the respondents have done one of those actions at least once and
$15.79 \%$ affirmed that they comment or rank negatively an app that have disappointed them. It's correlated with the reason why the user gave up to purchase an app, $24.21 \%$ do it when there is no much information available and $23.16 \%$ gave up when there is too much negative comments.

To iPhone users, the main feature of the store is the variety of Apps available, the users also like the store' suggestions and access a lot the Top Apps area, many users enjoy the possibility to search and browse the stores by different approaches (by category, by popularity, etc.). Many users have a perception that the store have a good usability and is easy to use. Some users pointed as a good aspect the optimized purchase experienced and how easy is to buy in the store. Other users do not pointed any particular aspect of the store as a killer feature, what they appreciate is the quality of the apps available there.

For good or for worst, content is one main issue in iPhone app store. Many users are aware that some apps, as games, are not available in Brazil, it is one of the main complains about the store, because of this limitation some users have accounts in other countries that they know that the wanted content is available. The users also commented that although the use of the store is pleasant and easy the search engine has some problems and it is more evident when they are searching for content that they know that exist but is not displayed in the search results or it is not one of the firsts results. Furthermore, some users pointed the need to additional search mechanism as filters. Since it is not possible to try and buy the apps, some users think that the store do not provide as many information as desirable about the app what sometimes results in a hesitation to purchase.

\subsection{Nokia Ovi Store}

From 88 responses of Ovi Store users, 64\% consists of male against $36 \%$ of female users, the most balanced distribution among all stores. The majority of them are in the age range of 21 to 30 years $(60.5 \%)$ but there were a good number of respondents between 31 to 40 years $(28.9 \%)$. Almost the totality of these users have been using computers for more than 4 years $(95.9 \%)$ and $78.7 \%$ of them had having a smartphone for more than 1 year. Greatest part of users have a under graduation degree (73.7\%) and from those, $51.5 \%$ of them have a graduation degree. 
The Nokia users are the least aware of the app store available to them, $8 \%$ reported that don't know or don't access the store. Nokia Ovi store had the highest number of responses when asked about search problems, from the results, $36.3 \%$ of users said that have frequent or high frequent problems when searching for an app. The store has highest number of unsatisfied users (33.3\%) although virtually there is no extreme opinions as high unsatisfied or high satisfied, $65.9 \%$ of the users think that there is few or no apps enough in the store. Ovi's users do not engage so much with the store, most of them never comment or ranked an app (72.3\%) and only $3.41 \%$ comment or ranked it negatively when disappointed with an app.

To the owners of a Nokia smartphone, Ovi store solve a problem to those users because it centralize there the content available for their devices, this feature, associate with the filter by device, was reported as one of the main advantages of the store. Centralized content in just one place is an important solution since find and download content was one of the main complains of these users [3]. Some users point that the store is easy to use, and appreciated the variety of apps. Ovi users are one of the most pragmatic among app store users, many of then reported that they access the store when they're looking for a specific content.

The main complain with Ovi store is related with the search engine and the lack of applications. The search engine can't find specific apps that the user knows it is available. The users have a perception that there are many similar apps in the store and the store do not effectively help them to decide which one to choose. Some users are not satisfy with the look and feel of the store and think that the navigation is problematic.

\subsection{BlackBerry App World}

From 23 responses of BlackBerry users, 83.3\% consists of male against $17.7 \%$ of female users. The most part consist of user in the age range of 21 to 30 years $(44.4 \%)$ or between 31 to 40 years $(44.4 \%)$. About computer usage, $88.9 \%$ of the respondents informed that they have been using computers for more than 4 years and only $16.7 \%$ have been using smartphones for less than 1 year. $88.9 \%$ of the respondents have a under graduation degree and from those only $22.2 \%$ have a graduation degree, what could be explained by the youth of the users.
A high number of users (68.75\%) had never commented or ranked an app and none of them have responded that ever commented negatively an app that have disappointed them. Almost all users have faced problems with apps downloaded from BlackBerry App World and the most common reason why they gave up from purchase an app it is because of the price $(26.09 \%)$ or because the purchase process was too long $(21.74 \%)$, for these users it seems too extensive. There are some complains about the search engine, $62.4 \%$ of users have faced some problems when searching for an app and from those $25 \%$ said that it happens frequently. About the number of apps available, some users pointed the absence of some apps available in other stores (eg.: Skype) and 43.75\% reported that there is few apps in their opinion.

BlackBerry users have almost the same complains as the users from other stores, they pointed usability, store look and feel and free applications as the main positive aspects of BlackBerry App World, the integration between mobile and desktop was also pointed as a good aspect of the store but some users pointed issue to install and synchronize apps. The price of the apps and lack of apps available in Portuguese were other aspects criticized by the users.

\section{Conclusion}

Though, the research do not represent exactly the Brazilian market the qualitative aspect of the responses and the occurrence of the same complains could provide a relevant data to understand the particularity of its market. However the amounts of responses vary from store to store, and their users have different issues and complains, there are some common problems that affect the all stores covered by the research. The first one is that all the stores have search issues. In all stores there have been cases of users reporting that the search engine didn't displayed an known existent app even when the search criteria was exactly the name of the application, according with the user perception. Other common point is that, in all stores, more than $80 \%$ of users had informed that they have an disappointment with an app or with the store, though more than $80 \%$ of all users considered themselves as satisfied or very satisfied with the store and the apps available there. The third common aspect is why the users gave up to buy an app, the main reason was application's price, in user perception it was to expensive, $35.88 \%$ of all users pointed it as impediment to buy an app, the exception was the android market when among those users it 
had only $18.78 \%$ of the responses tough it was the second most informed reason. Due to some legal pendency, some stores do not offer all their content in the Brazilian stores. In these cases, when the user search for the content that is not available in Brazil, the store just do not display it in the results in spite of that seamless behavior there are some uses that are aware of the stores limitation and its generate an disappointment to those users. The same feeling is present when apps that the user expected that are available but it is not (e.g.: Skype and Angry Birds). It's interesting to observe that although the store is a hermetic environment the users have a global perception and build their expectations by the possibilities of other stores, they know when an desirable app is available for other store and it is not for their, to these users it's the responsibility of the store/manufacturer to make it available, so the absence of an app is its fault.

Nonetheless, most of the users are satisfied with the applications available for their smartphones. The number of $19.2 \%$ of users unsatisfied or very unsatisfied with their app store shows there are lots of opportunities for improvements, some of the reasons depends of the maturity and evolution, as price perception. The reasons that are directly related with usability represents $31.3 \%$ of the total responses, these are related to an acquisition process too extensive and few information available. The other reasons are associated with disappointment with the apps, what is not directly related with store usability. The research also demonstrated there is no dominant process to search for an app, yet browsing by category is the most common, there are other alternatives that the users appreciate. It's also important to notice that these routines are not only constructed based on functionalities available in the store, some are performed outside the store, as ask friends and relatives about apps and search information on the internet.

\section{References}

[1] A. N Oppenheim. Questionnarie, Inteview and Attitude Measurement. PRINTER PUBLISHERS. LONDON. 1992

[2] Antonio Carlos Gil. Métodos e Técnicas de Pesquisa Social. Editora Atlas, São Paulo, 1985.

[3] Blog do Android. Vendas no Brasil de smartphones ultrapassarão as de desktop em 2011. Available in: http://www.blogdoandroid.com/2011/02/vendas-no-brasil-desmartphones-ultrapassarao-as-de-desktop-em-2011/ . Access date: September 19, 2011.

[4] Craig Goldwin, The art of the cart: Why people abandon shopping carts, Available in $<$ http://visibility.tv/tips/shopping_cart_abandonment.html > Access Date: August 28, 2010.

[5] Deborah J. Mayhew. The Usability Engineering Lifecycle: a practitionier's handbook for user interface design.

[6] Distimo Report, Available in < http://www.distimo.com/appstores/ > Access Date: August 28, 2010.

[7] G1. Penetração 'fraca' de smartphones anima Intel para futuro, diz presidente. Available in:

$<$ http://g1.globo.com/tecnologia/noticia/2011/03 /penetracaofraca-de-smartphones-anima-intel-para-futuro-dizpresidente.html> Access Date: August 28, 2010.

[8] Jakob Nielsen. Did poor usability kill e-commerce? Useit, Aug. 2001. Available in

$<\mathrm{http}: / /$ www.useit.com/alertbox/20010819.html $>$. Access Date: August 28, 2010.

[9] Kelvin Lopes Dias \& Djamel Fauzi Hadj Sadok. Internet Móvel: Tecnologias, Aplicações e QoS. Centro de Informática Universidade Federal de Pernambuco. Available in: $<$ http://rolopes.com/public_html/fatec/2007_1_metodo/exemp los/artigo/Artigo MobInternet.pdf $>$ Access Date: August 20, 2011.

[10] Lars-Erik Holmquist, Zeynep Ahmet. Sharing Mobile Services: Beyond the App Store Model, in: MobileHCI 2010, ed. ACM. Lisbon, Portugal. 2010.

[11] Nielsenwire. You Have and App for That... Now What? Available in: <checkar>. Acces Date: June 22, 2011

[12] Ralf Gordon and Egel Mikalajunaite. The Smartphone Application Market has Reached more than 2.2 Billion Dollars in The First Half of 2010. Available in

$<$ http://www.research2guidance.com/the-smartphoneapplication-market-has-reached-more-than-2.2-billion-dollarsin-the-first-half-of-2010/>. Access Date: August 28, 2010.

[13] Ricardo Cavallini Terence Reis. $1^{\text {a }}$ Pesquisa \#Mobilize Consumidor Móvel 2011. W/McCann, Grupo.Mobicom and Instituto Ipsos Mediact. Available in

$<$ http://www.xydo.com/toolbar/26516473-

consumidor m\%C3\%B3vel 2011>. Access Date: August 20, 2011.

[14] Seongil Lee. Mobile Internet Services from Consumers' Perspectives, in: Intl. Journal of Human-Computer Interaction, 25(5), Taylor \& Frances Group, 2009, pp 390-413.

[15] Stephanie Rieger. 8 Ways to Improve App Store User Experience. Available in

$<$ http://www.slideshare.net/bryanrieger/developing-aninterface-for-the-future-of-mass-market-softwaredistribution>. Access Date: August 28, 2010.

[16] OI Aplicativos. Available in < http://apps.oi.com.br/ > Access Date: 28 August 2010

[17] Young Eun Lee and Izak Benbasat. A Framework for the Study of Customer Interface Design for Mobile Commerce, in: International Journal of Electronic Commerce / Spring 2004, Vol. 8, No. 3, pp. 79-102. 